\title{
Educating Engineers Under a Social Justice Perspective
}

\author{
https://doi.org/10.3991/ijep.v10i3.13673 \\ Patricia P. Jiménez ${ }^{\bowtie}$, Jimena Pascual \\ Pontificia Universidad Católica de Valparaíso, Chile \\ patricia.jimenez@pucv.cl \\ Andrés Mejía \\ Universidad de Los Andes, Bogotá, Colombia
}

\begin{abstract}
Although the need for an engineering education oriented to public welfare and social justice has been acknowledged for many years, the efforts to put it in practice seem insufficient and a culture of disengagement still appears dominant. The aim of this article is twofold: (1) to examine beliefs and motivations of university faculty towards the social responsibility of engineers, and (2) to develop pedagogical principles to deal with the culture of disengagement in engineering. A survey-based quantitative study was conducted among faculty from a university in Chile. A factor analysis revealed two dimensions of social justice in their conceptions, with significantly higher scores for the first one: environmental/ethical versus public/community. Additionally, faculty value less the humanities and social sciences than other non-technical topics in the curriculum. Results, for this university, confirm the prevailing cultural features reported elsewhere. Some guidelines to counteract the cultural pillars of disengagement are based on critical thinking, context-based learning or situated practice, and interdisciplinary learning. These are illustrated in a course on Systems Simulation.
\end{abstract}

Keywords - Engineering education, engineering ethics, social justice, simulation modeling

\section{Introduction}

Significant efforts have been made in the last two decades to innovate the way engineers are trained. The process carried out to educate a lay person to become an engineer involves not only learning science, engineering and technology subjects and skills, but also socializing into the professional culture, attitudes and the values of engineering. The latter is a subtler aspect of engineering education. It occurs over conversations, friendship networks and professional experiences, such as internships and capstone design projects, when students engage with faculty, peers and fellow engineers. Where in this process do engineers-to-be learn about their potential contribution to society?

If, as Cech [1] points out, engineering students' interest in public welfare concerns actually decreases over the course of their college education, then perhaps the engineering education process does not teach students to reflect upon the social impact of their 
work. In light of this, this research sets out to understand the beliefs and values of faculty regarding social justice concerns and their relationship to the engineering profession, in order to derive implications and guidelines for the design of an engineering education process that integrates social justice perspectives. This work extends the results presented in Jiménez, Pascual \& Mejía [2]. As Riley [3] suggests, moving away from an apolitical or value-neutral view of engineering work requires teaching engineers to think critically, autonomously, understanding the context surrounding engineering problems, and taking time to discover what the right problem is, among other skills. These skills do align with engineering programs' declared learning objectives, as well as with outcomes proposed by engineering accreditation boards such as learning outcomes 2 and 4 by ABET [4].

This paper is organized as follows. First, the concept of social justice and its relation to engineering practice and education are introduced. This is followed by a description of the data collection methods used to obtain information on faculty beliefs regarding the relationship between social justice and engineering. Results are presented next, followed by guidelines for engineering education and an illustration of the pedagogical recommendations on an engineering course. Finally, this article presents conclusions and implications for practice and future work.

\section{Theoretical Framework}

\subsection{Social justice}

Social justice has to do with the (un)equitable conditions that people have to face in their living, which in turn depend on the social group each belongs to (Young [5]): the better or worse access to physical and cultural goods, the ways in which each person is addressed by others and how this defines social hierarchies, the cultural expectations others have about the kind of person each one should be and what their general place in society is, and even the way formal norms (e.g. laws and policies) affect what each person can or cannot do, among many other aspects. It is not the same to be a woman of an ethnic minority, living in poverty in a conservative religious environment, and with a lesbian identity, than to be a rich white man in the same conservative religious environment, with a heterosexual identity.

Historically, the emphasis of social justice has been put on the distribution of resources and goods among the members of a community (National Pro Bono Resource Centre [6]): Are they justly or equitably distributed? Of course, the criteria for such distribution are strongly contested. But the idea is guaranteeing that everybody has access to whatever they need to live a dignified life; as such, it bears a direct relationship with human rights [6]. As put by Rawls, "the subject matter of justice is the basic structure of society, or more exactly, the way in which the major social institutions (...) distribute fundamental rights and duties and determine the distribution of advantages from social co-operation" (quoted by Gerwitz [7]). The social variable class is central to the idea of distribution, as it describes how individuals stand in relation to their access to economic goods and resources. However, this variable does not only describe a result; 
it defines a person as a member of a social group -working class, middle class- insofar as belonging to it also bears a causal relationship, even if not deterministic, with their kind of access to such economic goods and resources in the future.

Although issues of distribution are still central, various authors have sought to broaden the reach of the social justice concept. One such attempt, currently widely used in the literature, can be found in Fraser's work [8] [9]. Her framework postulates three dimensions, and thus it is sometimes referred to as the Three Rs model. Traditional issues of (re)distribution are here complemented by aspects of recognition and political representation (or participation). None of these three dimensions can be reduced to the other two. Furthermore, Fraser shows that only very rarely cases of social injustice appear in one of these dimensions alone. For example, sometimes differences in status among social groups -which is a typical issue of recognition-may lead to their different possibilities to have access to good jobs, which will in turn lead to economic differences between them -which is an issue of distribution. In other cases, differences in economic power among social groups may give rise to differences in political power. The framework provided by the Three Rs model allows for an awareness not only of the various kinds of social justice issues that should be paid attention to, but also of the different types of social mechanisms by means of which social injustice can be produced.

\subsection{Social justice in engineering}

The literature on the relationship between engineering and social justice (e.g., [2] [3] [10] [11]), highlights the impact of engineering on society. This impact can occur in various ways, one of them being the side effects of implementing engineering designs, many of which are suffered by the environment. But this is a negative formulation of impact: it refers to the kinds of consequences of engineering designs that most would want to avoid. The exercise of a kind of engineering committed to social justice would of course be careful about side effects. But that commitment expresses something positive too: an ideal about the improvement, and not just avoiding a worsening of the state of social justice in the world today. This focus on questions regarding what engineering practices strive to achieve and how they contribute to justice, suggests a responsibility that falls on the engineer, which goes clearly beyond technical excellence. It touches on a much more general issue about the meaning and purpose of engineering practices.

The work of Ulrich [12] [13] [14] provides a critical systemic way to examine this. For him, any social system design -any policy, program, institution or action that intervenes in the human world, such as engineering designs- is unavoidably limited, as it can never fully take into account all the different aspects that could be relevant in the problem situation. As such, it draws a boundary that divides what is included and what is left out from consideration. It, therefore, embodies a perspective: a (necessarily restricted) way of seeing the situation and what must be done in it (Mejía, Mariño \& Molina [15]). Ulrich proposes twelve elements that define that boundary -and thus the specific ways in which they are chosen are called boundary judgements. Now, while drawing that boundary is inevitable, how it is drawn has implications for issues of justice and therefore it belongs to the domain of what those involved in the implementation of a social system design -including engineers-are ethically and politically responsible 
for. The perspective behind an engineering design can then be critically revealed and challenged by asking how the boundary judgements have been and ought to have been made: What are/is and what ought to be the system's: i) Beneficiaries, ii) Purpose, iii) Measure of improvement or success, iv) Decision-makers, v) Resources, vi) Environment, vi) Experts, vii) Expertise, viii) Guarantors of success, ix) Affected stakeholders $\mathrm{x})$ Possibilities of emancipation of the affected, $\mathrm{x}$ ) Worldview.

Interestingly, as shown by Ulrich's scheme of critical questions, the fact that engineers are brought as experts in a particular situation is already part of a perspective that both commissioners and engineers should be aware of, and whose limits should be questioned.

The three Rs of Fraser's theory of social justice can now help achieve a more nuanced understanding of the possible impacts of engineering designs on the beneficiaries and the affected, in terms of social justice -or injustice. As engineering has traditionally dealt with the manufacturing of goods and services, distribution issues readily come to mind: Who are or are not those goods and services for, who will benefit from having them and who will not? Issues of recognition and representation are perhaps less easy to recognize, but they are nevertheless there: In what ways may these goods and services reinforce stereotypes and ways of misrepresenting certain social groups? Are they excluding some people (e.g. by ability or age) by means of their design? Or, on the contrary, how are these goods and services helping individuals of certain underprivileged social groups overcome such stereotypes and ways of misrepresentation? Or in what ways are engineering products contributing to the creation of spaces and forms of political participation by under-represented social groups, for instance through new virtual ways of appearing in public for populations which traditionally have not had the opportunity to voice their positions, concerns, and worldviews?

\subsection{Social justice in engineering education}

If one believes that engineering education goes beyond the mere technical training in the tools of engineering and sees it as also having an ethical and political dimension, then the issues of social justice take center stage. This wide understanding of engineering education is now explicitly recognized by various universities -even if only in a nominal way- and other organizations - e.g. accreditation boards like ABET. Despite this acknowledgement, beyond perhaps one mandatory engineering ethics course, it is uncommon for engineering programs to offer courses (such as the one reported by Larsen \& Gärdebo [16]) or academic activities of other kinds, which directly deal with problems of social justice and the engineer's responsibility to society. Additionally, the question of whether individualistic values are attached to the exercise of engineering and transmitted to students through the hidden curriculum has almost not been investigated. Moreover, some authors identify a form of disengagement of engineering faculty and students from concerns of social justice [1]. Whilst such disengagement may be a general malady proper to contemporary times, the traditional purely-technical orientation of engineering education may make it especially prone to it. 
Cech [1] identifies 3 pillars associated to the engineering culture that contribute to a behavior of disengagement to public welfare concerns. These pillars are: 1 . Depoliticization, where cultural and social concerns are irrelevant to engineering practice, 2. Technical/Social Dualism, where engineers separate technical from social tasks and skills, and 3. Meritocratic Ideology, where success is believed to be a result of individual talent, and where the way things are done is not usually questioned (favoring the status quo). This paper seeks to understand whether these pillars are internalized by engineering faculty in a Latin American context, and extend these results to differentiate between social, ethical and environmental issues. This diagnosis would then be useful to propose some general educational principles that might help engineering professors and lecturers tackle the factors affecting disengagement from social justice and public welfare concerns. Ultimately, this research attempts to contribute to the promotion of engineers whose work is critically conscious and socially oriented.

\section{Methodology}

This research is structured in two phases. In the first phase, data was collected from engineering faculty and students using a mixed-methods approach. A quantitative study focusing on faculty beliefs was followed by a qualitative analysis of student motivations towards social justice. The elicitation and evaluation of student beliefs is not described in this article but it is reported in a complementary paper by the same authors [2].

The objective of the second phase of this research is to develop pedagogical counter measures that neutralize the effects of the three pillars of disengagement stated by Cech [1]. To this end, the literature on pedagogical methods and practices was surveyed to identify successful experiences in engineering courses. This information was complemented with faculty reports regarding their own knowledge and practices, which was informed in an open-ended survey question.

This study is conducted in a medium-sized university in Chile. The university organizes its activities in nine colleges with a diverse spectrum of disciplines. It has almost 18,000 students enrolled at the undergraduate and graduate levels. The research was carried out at the College of Engineering, where nearly 6,000 undergraduate students study in nine different engineering programs.

In order to identify faculty beliefs regarding social justice and the engineering profession, 53 engineering faculty answered an ad-hoc survey. Faculty responses were collected using an online questionnaire through a dedicated platform. The questionnaire is divided into four sections of either multiple choice (using a 4-point Likert scale) or order ranking questions, as well as one section with open-ended questions. The aim of the first section is to identify faculty beliefs regarding the engineering culture and the social role of the engineering profession (9 questions). The second section seeks to identify contributing factors of a successful engineering practice (4 questions). The purpose of the third section is to explore how faculty rank the relative importance of nontechnical contents in engineering education (5 questions). The fourth section of the questionnaire seeks to assess the relationship faculty find between social justice constructs and engineering practice (5 questions). The final section includes two open- 
ended questions, one of which asks for best practices and successful initiatives to include social justice themes into engineering programs.

In this survey, a high social desirability might be associated to most of the questions. Thus, the results are a better indication of contrast between different aspects of what is being inquired, rather than an opinion in absolute value.

Responses to the survey were scrutinized first with descriptive data analysis in order to obtain a central tendency and dispersion overview. For the first section of the survey, a factor analysis was carried out to identify the underlying variables, or dimensions, that allowed reducing the number of explanatory variables.

The scores calculated for the dimensions were used to test the inferential hypothesis of preference of one dimension over another. This hypothesis has to do with the cultural characteristic of meritocracy enunciated in the theoretical framework. The rest of the sections of the questionnaire, which relate to the other two cultural pillars, were analyzed only descriptively.

\section{$4 \quad$ Results and Discussion}

Sixty percent of the respondents of the survey were men (32) and $40 \%$ were women (21). From the total, 34 are full time faculty (64\%) and 19 are part-time lecturers (36\%). Most of the respondents mainly teach engineering sciences (34\%) or engineering specialties (34\%), followed by faculty that teach management subjects (18.9\%), basic sciences $(7.5 \%)$ and social sciences and humanities $(5.6 \%)$.

\subsection{Beliefs regarding the engineering culture and the social role of the engineering profession}

A factor analysis on the first section of the survey revealed two principal components that reciprocate to two different views or dimensions about what characterizes a socially responsible engineer. One dimension in engineering responsibility (based on 5 items and an alpha Cronbach for scale reliability of 0.83 ) refers to the public or community orientation of the engineering profession. The second dimension (based on 4 items and an alpha Cronbach for scale reliability of 0.72 ) refers to their environmental and ethical responsibility. A paired-samples t-test was conducted to compare responsibility orientations among engineering instructors for the environmental/ethical and public/community dimensions. Overall, there was a significant difference in the scores for environmental/ethical $(\mathrm{M}=3.48, \mathrm{SD}=0.465)$ and public/community $(\mathrm{M}=3.02, \mathrm{SD}=0.564) \mathrm{di}-$ mensions; $\mathrm{t}=6.914, \mathrm{p}<0.001$. These results suggest that, to a greater extent, respondents (engineering professors) associate the responsibility of engineers with an individual behavior that respects professional laws and regulations, more than with the behaviors in which engineers act together with other agents to solve community problems.

One may interpret that respondents are interested in public or community related problems. However, from the nature of the items included in the environmental/ethical responsibility component or dimension, their main focus seems to be on work and attitudes at an individual level. This may be analyzed through the lens of Fraser's first R, 
redistribution. According to Hasenfeld \& Rafferty [17], there are two ideologies around the perception of redistribution: one involves a strong belief in economic individualism and work ethics, and the other involves a belief in social rights and collective responsibilities. One may interpret that economic individualism and work ethics are aligned to the concept of meritocracy that is often present in the engineering discipline discourse and that Cech [1] identifies as a cultural pillar of disengagement to social concerns.

Table 1. Average response, by gender, for the environmental and ethical responsibility versus the public and community responsibility dimensions

\begin{tabular}{|l|c|c|c|c|}
\hline Gender & $\mathbf{n}$ & $\begin{array}{c}\text { Environmental and } \\
\text { ethical responsibility }\end{array}$ & $\begin{array}{c}\text { Public or community } \\
\text { responsibility }\end{array}$ & $\begin{array}{c}\text { Difference between means - } \\
\text { significance level }\end{array}$ \\
\hline Female & 21 & 3.52 & 3.17 & $\mathrm{p}<0.01$ \\
\hline Male & 32 & 3.45 & 2.93 & $\mathrm{p}<0.001$ \\
\hline Total & 53 & 3.48 & 3.02 & $\mathrm{p}<0.001$ \\
\hline
\end{tabular}

When compared through a one-way analysis of variance, the responsibility dimension of male and female respondents show that the effect of gender is not significant (Table 1). The 32 male faculty had an average ethical/environmental orientation score of 3.45 ( $\mathrm{SD}=0.477)$, whereas the group of 21 female faculty had an average score of $3.52(\mathrm{SD}=0.453)$. In this case $\mathrm{F}(1,51)=0.289, \mathrm{p}=0.593$. Although, in average, female faculty $(M=3.17, S D=0.556)$ obtained higher scores than male faculty $(M=2.93$, $\mathrm{SD}=0.556)$ in the public/community dimension, results do not show a significant difference between both groups at a 0.05 level $(\mathrm{F}(1,49)=2.491, \mathrm{p}=0.121)$. Although it is not possible to be certain about the significance of this difference given the sample size, this result still suggests that women might be more keen to relate engineering to public and community interests.

\subsection{Beliefs on the relationship between social justice issues and engineering practice}

The survey covered different questions to evaluate the strength of the relationship between social justice concepts (peace/non-violence, gender equity, care for the environment, poverty and public safety) and the engineering profession. Table 2 summarizes these results. Faculty identify the engineering profession more with social issues of poverty and care for the environment. This, on one hand, may suggest a traditional perspective of engineering that is aligned with the distributive dimension of social justice, where engineers are concerned with helping the poor have more access to wealth and societal goods through the production or transformation of material goods. One may speculate, on the other hand, that as different environmental effects have been publicly associated with engineering solutions, faculty may conceive engineers as having an important role in overcoming environmental challenges. This assessment should be further investigated. 
Contrary to the above, social justice issues of peace, safety and gender equity, associated more easily to the recognition and participation dimensions of social justice, may be harder to relate to the engineering profession due to their relative intangible nature. Although more difficult, engineers may still contribute to the recognition and participation dimensions by training themselves on a different kind of thinking, one that appreciates the relationship between the immaterial and material aspects of life. This brings about a need for a broader understanding, among faculty, of the engineering profession and its contribution to societal problems.

Table 2. Relationship between engineering and social justice

\begin{tabular}{|l|l|l|}
\hline \multicolumn{1}{|c|}{ Social Justice Issues } & \multicolumn{1}{|c|}{ None or weak relationship } & \multicolumn{1}{c|}{$\begin{array}{c}\text { Medium or strong relation- } \\
\text { ship }\end{array}$} \\
\hline Peace/non-violence & $49.1 \%$ & $50.9 \%$ \\
\hline Public safety & $37.7 \%$ & $62.3 \%$ \\
\hline Gender equity & $32.1 \%$ & $67.9 \%$ \\
\hline Poverty & $17.0 \%$ & $83.0 \%$ \\
\hline Care for the environment & $5.7 \%$ & $94.3 \%$ \\
\hline
\end{tabular}

These findings can be interpreted in the light of the cultural pillar of depoliticization. Depoliticization is understood as the belief that engineering is concerned with the technical design of systems and objects without any relation to the cultural and political context. Faculty responses assign relatively little value to those topics that would help students better understand the political and cultural implications of engineering work.

\subsection{Relevant topics in engineering education}

Faculty reported on the importance of non-technical topics in the education of engineering students. Although many of these questions may trigger aspirational responses (where all subjects are rated as important), the results in Table 3 show a tendency to value less the humanities and social sciences than other sampled topics.

Table 3. Relevant topics in engineering education

\begin{tabular}{|l|c|c|}
\hline \multicolumn{1}{|c|}{ Topics } & $\begin{array}{c}\text { Irrelevant or } \\
\text { not important }\end{array}$ & $\begin{array}{c}\text { Important or } \\
\text { very important }\end{array}$ \\
\hline Humanities and social sciences & $24.5 \%$ & $75.5 \%$ \\
\hline Basic and applied research skills & $22.6 \%$ & $77.4 \%$ \\
\hline Ethical, social and public engineering concerns & $7.5 \%$ & $92.5 \%$ \\
\hline Innovation and entrepreneurship & $5.7 \%$ & $94.3 \%$ \\
\hline Oral and written communication skills & $0.0 \%$ & $100.0 \%$ \\
\hline
\end{tabular}


While about a quarter of respondent's rate social sciences and humanities as unimportant, ethical and social concerns are highly valued for the engineering curriculum. This suggests that faculty in this college do not share a clear perspective on the role of humanities and social sciences in shaping student's understanding of the world in which they will practice engineering, including the ethical and socio-political issues of this world. Two issues may be raised in this regard: one has to do with how students could understand the engineering role in society more critically if aided by a social science perspective. A second issue is the possible predisposition, judgement or prejudice that faculty may have on the contribution of social sciences to the education of engineers.

\section{$5 \quad$ Some Guiding Principles for Incorporating Social Justice Elements into Engineering Education}

This section presents some general guidelines to counteract each of the pillars of the culture-of-disengagement described by Cech [1], so that a concern for social justice can be incorporated into engineering education. The guidelines are general in nature, and as such do not constitute specific activities or educational environments, which must be adapted to their particular contexts, students, engineering topics, and even to the professors themselves as they are individuals with particular preferences and areas of pedagogical expertise. This proposal is meant to especially address faculty, although it is expected that the effect of the proposed measures will also be transferred to students. Because of this, these guidelines do not deal with more general curricular aspects that would need to be addressed at the level of department or program. A summary of the proposed "methodological antidotes", or counteractions, can be found in Table 4, together with the main pedagogical dimensions involved in each antidote.

Table 4. Methodological antidotes to the pillars of a culture of disengagement

\begin{tabular}{|l|l|l|}
\hline $\begin{array}{c}\text { Cultural Pillar } \\
\text { (Cech [1]) }\end{array}$ & \multicolumn{1}{|c|}{ Pedagogical dimension } & $\begin{array}{l}\text { Pedagogical practices to counter } \\
\text { the culture of disengagement }\end{array}$ \\
\hline Meritocracy & $\begin{array}{l}\text { Critical thinking (Ulrich [13], Riley [3], Mejía } \\
\text { [18], Mejía, Mariño \& Molina [15], Larsen \& } \\
\text { Gärdebo [16]) }\end{array}$ & $\begin{array}{l}\text { Identifying and discussing the } \\
\text { normative implications of prob- } \\
\text { lem definitions, using critical heu- } \\
\text { ristics }\end{array}$ \\
\hline Depoliticization & $\begin{array}{l}\text { Context-based learning and situated practice } \\
\text { (Cumming-Potvin \& Curie [19]) }\end{array}$ & $\begin{array}{l}\text { Using real problems or realistic } \\
\text { contexts, interacting with actual } \\
\text { actors or stakeholders }\end{array}$ \\
\hline $\begin{array}{l}\text { Technical-so- } \\
\text { cial dualism }\end{array}$ & $\begin{array}{l}\text { Interdisciplinary learning (Spelt et al. [20], } \\
\text { Richter \& Paretti [21], Leydens \& Deters [22]) }\end{array}$ & $\begin{array}{l}\text { Interdisciplinary learning and } \\
\text { team teaching }\end{array}$ \\
\hline
\end{tabular}

The first of these pillars, meritocracy, seems to be dominant in contemporary culture and strongly propelled by the expansion of neoliberal ideology. Challenging it requires critical thinking. For Riley [3], critical thinking is characterized by the need to think and reflect upon issues in an autonomous manner, examining diverse perspectives and 
applying "questions that arise from morally deep or caring perspectives" (p. 112). But not any type of critical thinking will do. The dominant approach both in academic literature and educational policy focuses on logical argumentation and general cognitive skills. However, what is mostly needed is a form of critical thinking more directly attuned to the examination of perspectives about issues of social concern -such as Ulrich's scheme for questioning boundary judgements- that allows for the exploration of alternative, non-dominant perspectives.

Regarding depoliticization, the pedagogical antidote proposed is context-based learning and situated practice. Context based learning refers to using real life or realistic cases and examples while teaching, in order to give a context to the theoretical aspects of the class content. Cummings-Potvin and Currie [19] describe this as situated practice, where "the learned is immersed in literacies in or similar to real life worlds" (p.27). Getting in contact with real problems and having the opportunity to attend to other ways of seeing problem situations by other various actors and stakeholders can denaturalize the usually taken-for-granted perspectives that underlie a particular commissioning of an engineering project. That encounter of perspectives -which in many instances does not occur in a harmonious or conflict-free way- is precisely a defining aspect of the political nature of any engineering project. And that is where the consequences and implications of engineering practice are more clearly revealed and the ethical and political responsibility of engineers can be more clearly felt and thought.

As pointed out earlier, the technical-versus-social dualism in engineering training/curriculum requires from engineers-to-be, as Leydens and Lucena [23] put it, "to practice thinking not just technically or socially, but sociotechnically" (p. 2). This may be addressed by creating an interdisciplinary context in which students have the opportunity to explore how these dimensions can be articulated or integrated, and not merely be deployed in parallel but then also in isolation from each. For Spelt et al. [20], thinking in an interdisciplinary manner is necessary "to advance understanding when analyzing and solving complex societal problems. Interdisciplinary team outcomes are results of the exchange of disciplinary knowledge and (inter-)disciplinary skills among team members" (p.761). In engineering education, this idea seems to have taken some hold, as a growing number of initiatives that seek to incorporate interdisciplinarity are reported in the literature (Richter \& Paretti, [21]).

Granting that it is unlikely that a single person will develop the ability to see and study a problem situation from all the relevant disciplinary perspectives, it is necessary to develop some intercultural awareness and a disposition to constructively interact with others who have other disciplinary perspectives. Intercultural awareness can be boosted, for Leydens and Deters [22], "via engineering projects that involve diverse levels of public and/or community engagement" (p.1). However, they also question "whether such engagement results in greater intercultural development among engineering students" (ibid.). As it does not happen in an automatic way, it is then a task for engineering educators to create the environment most appropriate for that to occur. One possibility for the practice of interdisciplinary learning comes from the growing interest in entrepreneurship in engineering and other majors (see Table 3). Additionally, team-teaching with lecturers or practitioners from other disciplines would 
also enable a richer deliberation upon the technical/social duality that arise when attempting to solve engineering problems.

These guiding principles can help faculty in designing new ways of educating engineers-to-be at various levels. Therefore, they allow for a partial implementation with different degrees of commitment from professors and lecturers who want to orient their classes towards an engineering that cares for social justice, but also who want to make larger curricular changes in their undergraduate or postgraduate programs. A modular approach might help overcome the reluctance that some engineering faculty may have with integrating a social justice perspective to their technical courses, by offering them the chance of experimenting first with small-scope changes to their curricular and pedagogical designs, and learning, little by little, what it implies to bring social justice concerns into engineering education.

\section{$6 \quad$ An Illustration}

This section illustrates some pedagogical strategies that seek to counter the effects of the culture-of-disengagement [1]. These examples come from a Systems Simulation course. The course focuses on discrete event simulation modeling and analysis. In the following subsections, it is first shown how the learning objectives may be adapted so that they would be better oriented towards a social justice perspective. Then, two examples of learning activities are presented and their potential or intended impact on student and faculty engagement is then briefly discussed.

\subsection{Social justice learning objectives}

For the simulation course illustration, the syllabus may be extended to include new learning objectives that will contribute to the program's learning outcomes in social welfare. Examples of these objectives are:

1. To analyze the strengths and weaknesses of simulation as a tool to model different productive and social systems

2. To identify the boundaries of a system and how these boundaries might be different under different contexts and perspectives

3. To recognize the existence of asymmetries in knowledge, power and other social variables, when developing solutions to problems using simulation

4. To build simulation solutions with consideration of public welfare, as well as social, environmental and economic factors.

These learning objectives may be attained through different class and homework activities such as the ones presented next. Organizing these activities is in itself an antidote for faculty's perceived disengagement to social issues, as faculty commit to these topics when preparing class material or when interacting with guest speakers. 


\subsection{Simulation activity 1: modeling a simple queuing system}

This activity, that can be implemented early in the course, consists of documenting the conceptual model of a simulation project for a simple system such as a cafeteria shop. The initial steps of the project require identifying the objective to be evaluated through simulation, the data needed to represent the system, the modeling assumptions, and the design parameters (e.g., queuing policy), among others. This activity may be extended to include the following boundary questions [12]:

1. What should the purpose of this system be?

2. Which performance measures should be monitored? How should success be measured?

3. From whose perspective is this being modeled? Who should be interested in these results? Who are the stakeholders?

4. What other experts should participate in this project?

The purpose of these additional questions is to motivate discussion on the different objectives that different stakeholders may have regarding the system or the simulation study. The first step is to recognize that there are several stakeholders, not just the person that commissioned the study. The second step is to identify the existence of multiple objectives and realize that these might be in conflict, as improving one objective might worsen another. In addition, the discussion may lead to identifying relevant information holders that should be invited to participate and whose knowledge and experience should be recognized.

To enrich discussion on objective definition and stakeholder identification, a preclass reading, such as Sturrock [24], may be assigned. A reflection on engineering tools and social justice issues may lead to topics such as the ethical responsibilities of the engineering profession, the consequences and limitations of the use of tools and technology, the reproduction of power imbalances between those who understand the use of these tools and those that don't, and even other public welfare issues such as poverty, inclusion and equity. This discussion exercises student's critical thinking abilities, as a countermeasure for the meritocracy cultural pillar of disengagement.

\subsection{Simulation activity 2 : modeling a complex system}

The purpose of this exercise is to simulate a realistic system. This can be a semester long project that runs in parallel to simulation lectures (covering topics such as conceptual modeling, input analysis, model programming in a simulation language and output analysis), and it can also be a capstone project for senior year students. Students apply their simulation knowledge in a project that requires investigating a real system (such as a container depot, a health clinic or a call center), or, if as part of a class, a case-study describing relevant information about a realistic system. Martin [25] presents an interesting cross-dock process case study that includes instructor notes.

The first step of the project is to build a conceptual model, which is helpful when discussing the understanding of the problem with different stakeholders, that share different perspectives about the system's objectives. Both conceptual the modeling [26] 
[27] and the boundary questions [12] assist students in their critical analysis of the system to counteract the cultural pillar of meritocracy.

If using this activity to counter the effects of the cultural pillars of depoliticization or technical-social dualism, the perspective of a sociologist may complement the technical discussion by raising political and cultural concerns. For example, if modeling a major street intersection, an evaluation of a dedicated lane to public transportation, a bikeway or a longer crossing light for elderly pedestrians, will enrich the otherwise usual engineering perspective of flow efficiency. Furthermore, having an architect, a sociologist or a faculty from a different discipline act as a project co-advisor to the students, will provide a rich interdisciplinary opportunity for understanding the problem from different angles.

When the instructor organizes an industrial visit or invites a professional to give a talk about the system, it facilitates both faculty and student engagement with social concerns. One may even go further and have students discuss the results at a public venue, such as a blog, a radio station, a community meeting or a letter to the editor of a local newspaper. This would challenge both faculty and students to take action and practice the professional involvement of engineering in society.

\section{$7 \quad$ Conclusion and Implications for Practice}

The purpose of this research was to examine beliefs and motivations of university faculty towards the social responsibility of engineering. From the results, it seems that the cultural pillars of disengagement in engineering are present to some extent among surveyed professors. Their beliefs on the engineer's responsibility are closer to an environmental/ethical perspective than to a public/community perspective. Surveyed professors value less the contribution of social sciences and humanities to engineering education when compared against other non-technical topics. Also, they do not seem to recognize the wide spectrum of the societal implications of engineering practices. All these findings allude to cultural values of engineering centered around an individual with lower valuation of social issues when compared to technical issues, that detaches of engineering designs from their political and cultural circumstances. Since these findings may be somewhat limited by the questionnaire design, future research needs to deal with social desirability issues in order to improve the understanding of these results. Gender differences are apparent, with women perceiving a stronger role of engineering in public/community issues. Although this result cannot be confirmed at a 0.95 significance level, it would be worth to explore it further.

This research also sought to develop guidelines to counteract the culture of disengagement in engineering education. Some strategies are proposed to complement the distinctive cultural values of engineering with social justice criteria that support the education of socially responsible professionals with an important role to play in relation to public and social problems. It would be interesting to explore whether a program with a social justice perspective could motivate more students to study engineering, especially those from groups that have been typically underrepresented in engineering schools. 
An final contribution of this work was the illustration of pedagogical strategies and their implementation on an engineering course. Future research shall validate whether these strategies contribute in balancing out the disengagement cultural pillars discussed here.

\section{$8 \quad$ References}

[1] Cech, E. A. 2014. Culture of disengagement in engineering education? Science, Technology, \& Human Values, 39(1), 42-72 https://doi.org/10.1177/0162243913504305

[2] Jiménez, P., Pascual, J., \& Mejía, A. 2019. Towards a pedagogical model of social justice in engineering education. Proceedings of the 8th International Conference on Software and Information Engineering, 55-59, ACM https://doi.org/10.1145/3328833.3328861

[3] Riley, D. 2008. Engineering and social justice. Synthesis Lectures on Engineers, Technology, and Society, 3(1), 1-152.

[4] ABET. 2018. Criteria for Accrediting Engineering Programs, Baltimore, MD.

[5] Young. I. M. 2000. Inclusion and democracy. Oxford: Oxford University Press.

[6] National Pro Bono Resource Centre. 2011. What is Social Justice? Occasional paper \#1. https://probonocentre.org.au/wp-content/uploads/2015/09/Occ_1_What-is-Social-Justice_FINAL.pdf

[7] Gewirtz, S. 1998. Conceptualizing social justice in education: Mapping the territory. Journal of Education Policy, 13(4), 469-484. https://doi.org/10.1080/0268093980130402

[8] Fraser, N. 2008. La justicia social en la era de la política de identidad: redistribución, reconocimiento y participación. Revista de Trabajo, 4(6), 83-99. https://doi.org/10.2307/j. ctvndv76q.7

[9] Fraser, N. 2008. Scales of justice: Reimagining political space in a globalizing world. Cambridge: Polity Press.

[10] Leydens, J. A., \& Lucena, J. C. 2017. Engineering justice: Transforming engineering education and practice. John Wiley \& Sons.

[11] Nasser, R. N., \& Romanowski, M. 2016. Social Justice and the Engineering Profession: Challenging Engineering Education to move Beyond the Technical. In Advances in Engineering Education in the Middle East and North Africa, M. Abdulwahed et al. (Eds.), Springer International Publishing, Switzerland. https://doi.org/10.1007/978-3-319-15323$\underline{0 \_17}$

[12] Ulrich, W. 1987. Critical heuristics of social systems design. European Journal of Operational Research, 31(3), 276-283.

[13] Ulrich, W. 2017. Systems thinking as if people mattered. Part 1/2: A plea for boundary critique (a new civil competence). http://wulrich.com/downloads/bimonthly_september2017.pdf

[14] Ulrich, W. 2017. Systems thinking as if people mattered. Part 2/2: Practicing boundary critique. http://wulrich.com/downloads/bimonthly_november2017.pdf

[15] Mejía, A., Mariño, J. P., \& Molina, A. 2019. Incorporating perspective analysis into critical thinking performance assessments. British Journal of Educational Psychology. Early view article. https://doi.org/10.1111/bjep.12297

[16] Larsen, K, \& Gärdebo, J. 2017. Retooling Engineering for Social Justice: The use of explicit models for analytical thinking, critical reflection, and peer-review in Swedish engineering education. International Journal of Engineering, Social Justice and Peace, 5(1-2), 13-29. https://doi.org/10.24908/ijesjp.v5i1.8928 
[17] Hasenfeld, Y., \& Rafferty, J. A. 1989. The determinants of public attitudes toward the welfare state. Social Forces, 67(4), 1027-1048 https://doi.org/10.2307/2579713

[18] Mejía, A. 2009. Tres esferas de acción del pensamiento crítico en ingeniería. Revista Iberoamericana de Educación, 49(3), 5-6

[19] Cumming-Potvin, W., \& Currie, J. 2013. Towards new literacies and social justice for engineering education. International Journal of Engineering, Social Justice, and Peace, 2(1), 21 37. https://doi.org/10.24908/ijesjp.v2i1.3516

[20] Spelt, E. J. H., Luning, P. A., van Boekel, M. A., \& Mulder, M. 2017. A multidimensional approach to examine student interdisciplinary learning in science and engineering in higher education. European Journal of Engineering Education, 42(6), 761774https://doi.org/10.1080/03043797.2016.1224228

[21] Richter, D. M., \& Paretti, M. C. 2009. Identifying barriers to and outcomes of interdisciplinarity in the engineering classroom. European Journal of Engineering Education, 34(1), 29 45. https://doi.org/10.1080/03043790802710185

[22] Leydens, J. A. \& Deters, J. 2017. Confronting intercultural awareness issues and a culture of disengagement: An engineering for social justice framework. In 2017 IEEE International Professional Communication Conference (ProComm), 1-7 https://doi.org/10.1109/ ipcc.2017.8013957

[23] Leydens, J. A., \& Lucena, J. C. 2016. Making the invisible visible: Integrating engineeringfor-social-justice criteria in humanities and social science courses. Proceedings for the American Society for Engineering Education Annual Conference, 111 https://doi.org/10.18260/p.25671

[24] Sturrock, D. T. 2018. Avoid failures!: tested success tips for simulation project excellence. Proceedings of the 2018 Winter Simulation Conference. Edited by M. Rabe, A.A. Juan, N. Mustafee, A. Skoogh, S. Jain, and B. Johansson, Piscataway, New Jersey: IEEE, 252-260 https://doi.org/10.1109/wsc.2018.8632366

[25] Martin, N. 2018. Bringing students to practice: performing a real-life simulation study in an introductory simulation course. Proceedings of the 2018 Winter Simulation Conference Edited by M. Rabe, A.A. Juan, N. Mustafee, A. Skoogh, S. Jain, and B. Johansson, Piscataway, New Jersey: IEEE, 4014-4025 https://doi.org/10.1109/wsc.2018.8632512

[26] Robinson, S. 2015. A tutorial on conceptual modeling for simulation. Proceedings of the 2015 Winter Simulation Conference. Edited by L. Yilmaz, W. K. V. Chan, I. Moon, T. M. K. Roeder, C. Macal, and M. D. Rossetti, Piscataway, New Jersey: IEEE,1820-1834

[27] Kashefi, A., F. Alwzinani and D. Bell. 2018. Perspectives on teaching modeling and simulation in a department of computer science. Proceedings of the 2018 Winter Simulation Conference. Edited by M. Rabe, A.A. Juan, N. Mustafee, A. Skoogh, S. Jain, and B. Johansson, Piscataway, New Jersey: IEEE, 4058-4068 https://doi.org/10.1109/wsc.2018. $\underline{8632516}$

\section{Authors}

Patricia P. Jiménez received an Industrial Engineering degree from Pontificia Universidad Catolica de Valparaiso (PUCV), and a M.Sc. degree in Engineering from Pontificia Universidad Catolica de Chile. She is currently pursuing a PhD degree in Education and Social Justice in the United Kingdom. She works as a lecturer at the School of Industrial Engineering at PUCV. Her research interests are engineering education, 
management and societal implications of engineering profession. Email: patricia.jimenez@pucv.cl

Jimena Pascual received her Industrial Engineering degree from PUCV, and M.Sc. and $\mathrm{PhD}$. degrees in Industrial Engineering from Purdue University, United States. She is currently an associate professor in the School of Industrial Engineering at PUCV. Her research interests are simulation modeling, logistic systems and engineering education Email: jimena.pascual@pucv.cl

Andrés Mejía received his Industrial Engineering degree from Universidad de los Andes, Colombia, a M.Sc. degree in Industrial Engineering from the same university, and a PhD degree in Management from the University of Hull, United Kingdom. He is presently an associate professor at the Faculty of Education, Universidad de los Andes. His interests include critical citizenship education, systems thinking and practice, engineering education. Email: jmejia@uniandes.edu.co

Article submitted 2020-02-09. Resubmitted 2020-02-27. Final acceptance 2020-02-28. Final version published as submitted by the authors. 